\title{
The relationship of FOXP3 expression and clinicopathological characteristics in adult T-cell leukemia/lymphoma
}

\author{
Kennosuke Karube ${ }^{1, *}$, Ryosuke Aoki ${ }^{1}$, Yasuo Sugita ${ }^{1}$, Shiro Yoshida ${ }^{1}$, Yuko Nomura ${ }^{2}$, \\ Kay Shimizu $^{1}$, Yoshizo Kimura ${ }^{1}$, Keiko Hashikawa ${ }^{1}$, Morishige Takeshita ${ }^{3}$, \\ Junji Suzumiya ${ }^{4}$, Atae Utsunomiya ${ }^{5}$, Masahiro Kikuchi ${ }^{6}$ and Koichi Ohshima ${ }^{1}$ \\ ${ }^{1}$ Department of Pathology, School of Medicine, Kurume University, Kurume, Japan; ${ }^{2}$ Department of \\ Pediatrics, School of Medicine, Fukuoka University, Fukuoka, Japan; ${ }^{3}$ Department of Pathology, School \\ of Medicine, Fukuoka University, Fukuoka, Japan; ${ }^{4}$ Department of Internal Medicine, School of Medicine, \\ Fukuoka University, Fukuoka, Japan; ${ }^{5}$ Department of Hematology, Imamura Bun-in Hospital, Kagoshima, \\ Japan and ${ }^{6}$ Chairman of the Board, Murakami Karindoh Hospital, Fukuoka, Japan
}

\begin{abstract}
Adult T-cell leukemia/lymphoma is an aggressive malignant disease associated with regulatory $\mathrm{T}$ cells as discussed in some recent reports. We analyzed the expression of FOXP3, a key molecule of regulatory T cells, in adult T-cell leukemia/lymphoma and its association with clinicopathological features. Of 169 adult T-cell leukemia/lymphoma cases examined, 60 (36\%) showed FOXP3 expression in lymphoma cells. Morphologically, 22 cases were classified as anaplastic large cell variant and 147 as pleomorphic cell variant. Only 1 (5\%) of the anaplastic large cell variant cases and 59/147 (40\%) of the pleomorphic cell variant cases expressed FOXP3. Epstein-Barr virus-infected cells were significantly more frequently found in FOXP3( + ) cases (23/60; 38\%) than in FOXP3 $(-)$ cases $(12 / 109 ; 11 \%)(P<0.0001)$. Cytogenetic analysis showed that FOXP3 $(+)$ cases had simpler chromosomal abnormalities than FOXP3(-) cases. Clinically, FOXP3(+) and FOXP3(-) cases did not differ significantly in age distribution, clinical stage, lactate dehydrogenase and calcium in serum and overall survival. However, 8 of 34 FOXP3 $(+)$ cases suffered a severe infectious state, an indication of immunosuppression, while only 2 of 62 FOXP3 $(-)$ cases did so $(P<0.005)$. FOXP3 expression in adult T-cell leukemia/lymphoma thus reflects morphological features and is clinically and pathologically associated with an immunosuppressive state.
\end{abstract}

Modern Pathology (2008) 21, 617-625; doi:10.1038/modpathol.2008.25; published online 1 February 2008

Keywords: adult T-cell leukemia/lymphoma; FOXP3; immunosuppression; prognosis; Epstein-Barr virus

Adult T-cell leukemia/lymphoma (ATLL) is a lymphoproliferative disorder (LPD) caused by human T-cell lymphotropic virus type-1 (HTLV-1) infection, which is highly endemic, especially in southern Japan and the Caribbean basin. ${ }^{1}$ In general, ATLL shows rapid progression, drug resistance and poor prognosis. ${ }^{1}$ ATLL cells are believed to be derived from post-thymic helper $\mathrm{T}$ cells with a phenotype of CD $4+$ and CD25 + . However, ATLL cells are not regarded as having a helper function; on the contrary, they have demonstrated a strong immunosuppressive activity in vitro. ${ }^{2}$ In fact, ATLL

Correspondence: Dr K Karube, MD, Department of Pathology, School of Medicine, Kurume University, 67 Asahi-machi, Kurume-shi, Fukuoka-ken 830 0011, Japan.

E-mail: karube1975@yahoo.co.jp

*JSPS Research fellow.

Received 24 November 2007; revised and accepted 7 January 2008; published online 1 February 2008 is involved in opportunistic infections more frequently than other lymphoma, ${ }^{3}$ such as Pneumocystis carinii pneumonitis ${ }^{4}$ and Strongyloidiasis. ${ }^{5}$ Furthermore, impaired cell-mediated immunity in this disease has been well documented. ${ }^{6}$

Recent reports have characterized regulatory $\mathrm{T}$ cells, known as Tregs, in terms of coexpression of CD4 and CD25. ${ }^{7}$ Upon T-cell receptor stimulation, Tregs potently suppress the activation/proliferation of other CD4 $+\mathrm{T}$ cells and CD8 $+\mathrm{T}$ cells in an antigen-nonspecific manner ${ }^{8}$ and in vivo usually serve to protect the host against the development of autoimmunity. ${ }^{9-11}$ But in some malignant neoplasms, for example, pancreatic and breast carcinoma ${ }^{12}$ and B-cell lymphoma, ${ }^{13}$ Tregs suppress the reaction of lymphocytes to tumor antigens and induce malignant neoplasm progression. Recent studies have also shown that Tregs help malaria parasites avoid host immunity. ${ }^{14}$ These findings indicate that Tregs sometimes account for unfavorable 
immunodeficiency and it is possible that abnormal Treg proliferation may also induce an unfavorable immunosuppressive state.

FOXP3 represents a new T-cell marker considered to be more specific for Treg cells than other markers such as CD4 and CD25. ${ }^{15-18}$ Gene transfer of FOXP3 converts naïve CD4 $+\mathrm{CD} 25-\mathrm{T}$ cells into a regulatory phenotype in both mice and humans, thus making this molecule a functionally important marker of this Treg-cell population. ${ }^{17-19}$

After the existence of Tregs with a distinct phenotype similar to that of ATLL cells had been substantiated, we evaluated ATLL cells in terms of Treg cells and demonstrated FOXP3 expression in some ATLL cells, a finding supported by some other reports. ${ }^{20-23}$ Furthermore, recent studies have found that one of the functions of FOXP3(+) ATLL cells is a Treg-like suppressive activity. ${ }^{23-26}$ Roncador et $a l^{22}$ reported that FOXP3 was a specific marker of ATLL in peripheral T-cell lymphoma. ${ }^{22}$ We can therefore assume that some ATLL cells express FOXP3 and may be derived from Tregs. However, FOXP3negative (-) ATLL cases are regularly identified but the frequency of these cases has not been well established, and no studies have attempted to analyze the pathological and clinical implications of FOXP3 expression in ATLL. In the study presented here, we compared FOXP3 $(+)$ ATLL and FOXP3(-) ATLL both clinically and pathologically to establish the importance of FOXP3 expression in ATLL cases.

\section{Materials and methods}

\section{Biological Materials}

The study population consisted of 110 cases retrieved from the archives of the Department of Pathology, Fukuoka University (1992-2005), to which 59 cases were added from the archives of the Department of Pathology, Kurume University (2005-2006). All samples were from lymph nodes and were obtained with informed consent and with the approval of the doctors of the participating hospitals. Serological tests had proved that the peripheral blood of all patients was positive for anti-adult T-cell leukemia/lymphoma-associated antigen. Parts of the tissue samples were formalinfixed, paraffin-embedded and then stained with the hematoxylin-eosin method. Two hematopathological specialists (KO and $\mathrm{MK}$ ) reviewed all cases.

Clinical information was obtained by reviewing the tumor registry records and/or the patients' medical charts.

\section{Morphological Variants of ATLL}

For this study, we established three morphological variants mainly by following the new WHO classification. ${ }^{1}$ First, we divided the cases into diffuse pleomorphic cell variant, which is the most common variant, and anaplastic large cell variant (ALCL). ${ }^{1,27-29}$ The pleomorphic cell variant was then subdivided into (1) pleomorphic cell variant, mediumsized cells predominant (pleo medium), and (2) pleomorphic cell variant, large cells predominant (pleo large). Both pleo medium and pleo large types show diffuse proliferation of atypical cells with irregular nuclei and coarse chromatin, but the pleo medium type is mainly ( $>50 \%$ ) composed of medium-sized cells (Figure 1a) and the pleo large type mainly $(>50 \%$ ) large cells (Figure 1b). The so-called small-cell variant of ATLL1 was included in the pleo medium type. The ALCL shows diffuse proliferation of atypical large lymphoid cells with oval or 'kidneyshaped' nuclei and abundant cytoplasm (Figure 1c), and lymphoma cells are usually positive for CD30 (Figure 1d). In some of these, a cohesive pattern was detected, indicating the presence of 'anaplastic large cell lymphoma'. Two Hodgkin-like ATLL ${ }^{30}$ cases and one AILT-like ATLL ${ }^{31}$ case were excluded from this study because they are extremely rare variants.

\section{Evaluation of Immunodeficient State}

We asked the participating clinicians whether any patients suffered from infection during the course of the disease. Almost all of them experienced some infectious state, for example, fever, elevated inflammation-associated protein (C-reactive protein, etc) and upper respiratory tract infection. However, to detect a 'severe and definitive' infectious state as an indication of an immunosuppressive state, we excluded cases with an inflammatory/infectious state during neutropenia (neutrophils in peripheral blood: $<500 / \mu$ l) after chemotherapy or during the end stage (in this study, during 3 weeks before death).

\section{Immunostaining}

Paraffin sections from each of the samples were immunostained with monoclonal antibodies against CD4 (Nichirei, Tokyo, Japan), CCR4 (PharMingen, San Diego, CA, USA), CD25 (Novocastra, Newcastle, UK), CD30 (DakoCytomation, Kyoto, Japan) and FOXP3 (eBioscience, San Diego, CA, USA), using heat-mediated antigen retrieval. A tissue sample was considered positive if more than $30 \%$ of the tumor cells were positive. Frozen sections were used for staining with the antibody against CCR8 (Genentech, Minneapolis, MN, USA).

\section{In Situ Hybridization}

Epstein-Barr virus (EBV)-encoded small RNA (EBER) was detected by in situ hybridization, using the EBER-PNA probe kit (DakoCytomation) according to the manufacturer's instructions. The evaluation was positive if positive cells were evident and accounted for more than $1 \%$ of the scattered cells (Figure 1e) with reference to the grading reported by Dupuis et al. $^{32}$ 

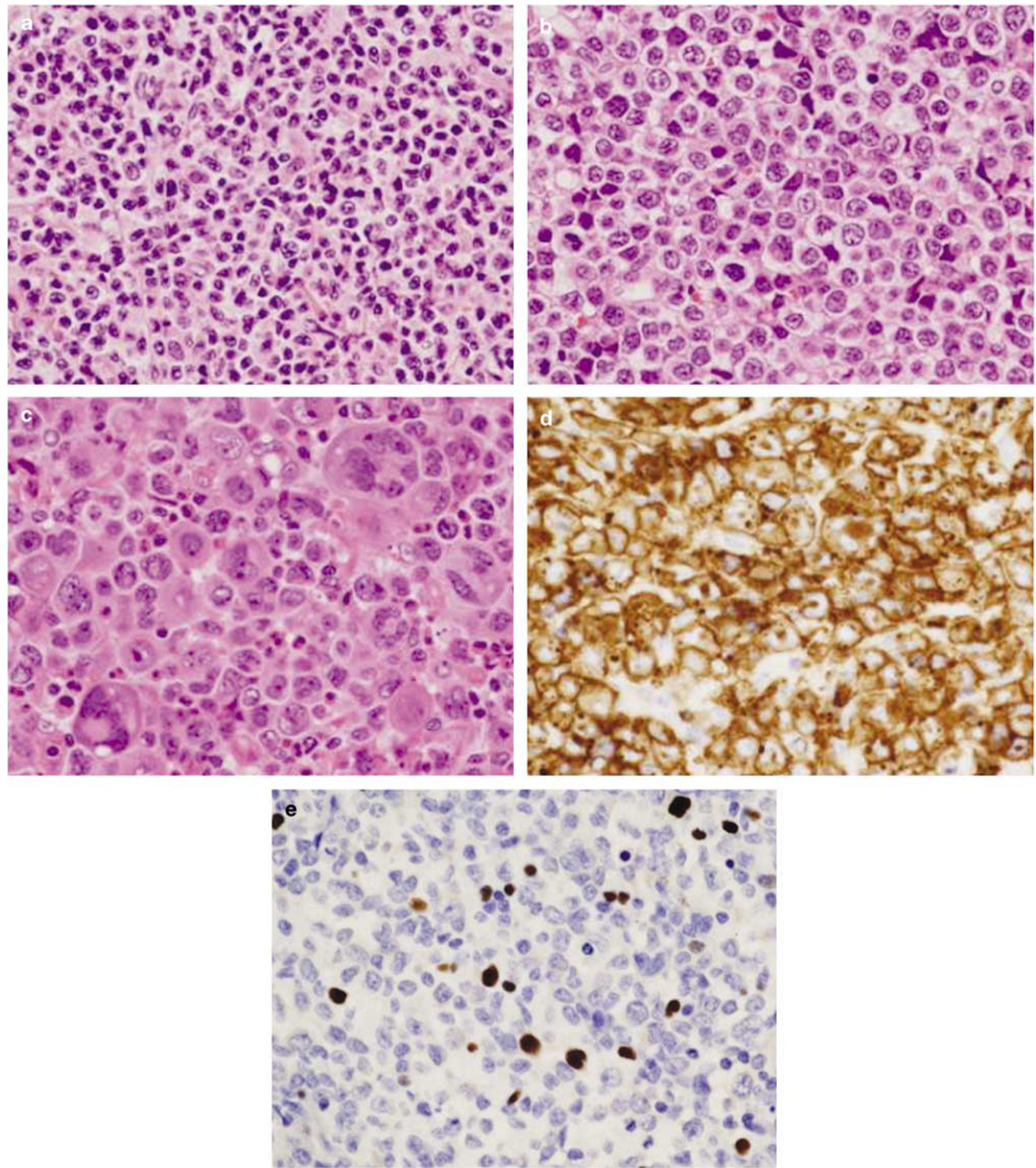

Figure 1 (a-d) Morphological variants of ATLL. (a, b) The majority of cases showed diffuse proliferation of pleomorphic lymphoma cells. (a) Some cases were mainly composed of small- to medium-sized atypical lymphoid cells whereas (b) large cells were evident in some cases. (c) An ALCL composed of large lymphoma cells with 'horse-shoe' or 'kidney-like' nuclei and abundant cytoplasm. Multinucleated giant cells also scattered. (d) ALCL. Large lymphoma cells, including multinucleated giant cells, are positive for CD30. (e) EBV was detected by in situ hybridization. This figure shows scattered EBV-infected cells. EBER in situ hybridization. (f , g) FOXP3 expression in ATLL. (f) About 70\% of lymphoma cells were positive for FOXP3. (g) Almost all lymphoma cells were negative for FOXP3. Two centrally located small cells, positive for FOXP3, were considered to be non-lymphoma cells because they lacked nuclear atypia. Original magnification for all figures: $\times 400$. 


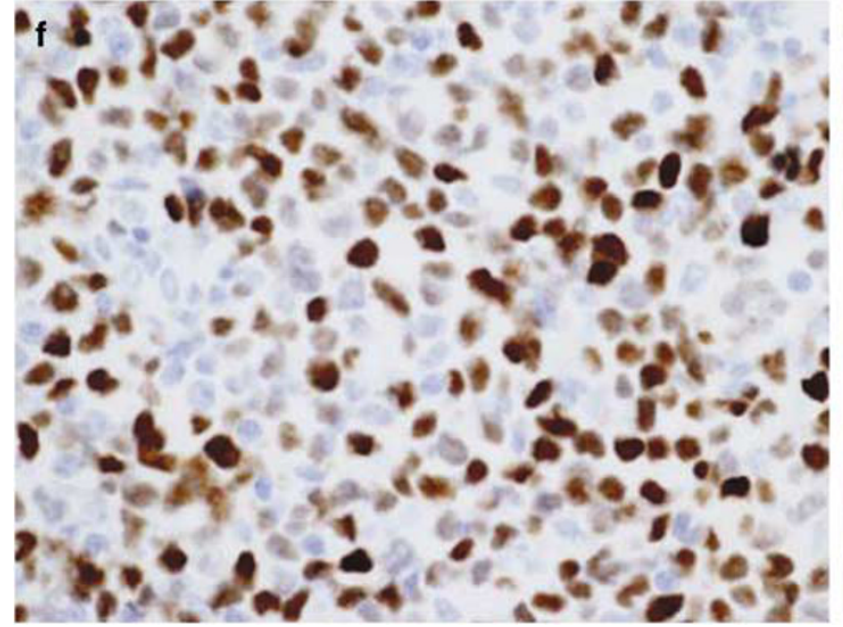

Figure 1 Continued.

\section{Southern Blot Analysis and Cytogenetic Analysis}

The remaining parts of the tissue samples were frozen and used for DNA isolation and gene analysis. The monoclonal or oligoclonal integration of HTLV-1 pro-viral DNA was examined by means of digestion with EcoRI, as described previously, ${ }^{33}$ and all cases (169 cases) were found to have pro-viral integration. The usual G-banding method was used for cytogenetic analysis. Karyotypes were described according to the International System for Human Cytogenetics Nomenclature (1995). Numbers of chromosomal breaks from structural abnormalities were calculated as the sum of all breaks whose derivation by band could be identified in the stemline karyotype. Marker chromosomes were not included in the analysis of numbers of chromosomal breaks. Multiple rearrangements of the same break site observed in the same patient were recorded separately.

\section{Statistical Analysis}

Student's $t$-test and $\chi^{2}$ test were used for comparisons of clinical and pathological findings among different groups. Survival curves were calculated with the Kaplan-Meyer method. The log rank test was used for survival analysis. A $P$-value less than 0.05 was considered to denote a statistically significant difference.

\section{Results}

\section{FOXP3 Expression and Histological Findings}

Of the total 169 cases, 147 (87\%) were classified as pleomorphic cell variant and $22(13 \%)$ as ALCL (Figure 1c and d). ${ }^{1,27-29}$ Of the former, 71 cases $(48 \%$ ) were classified as pleo medium (Figure 1a) and $76(52 \%)$ as pleo large (Figure 1b). Sixteen cases of ALCL were analyzed with regard to CD30

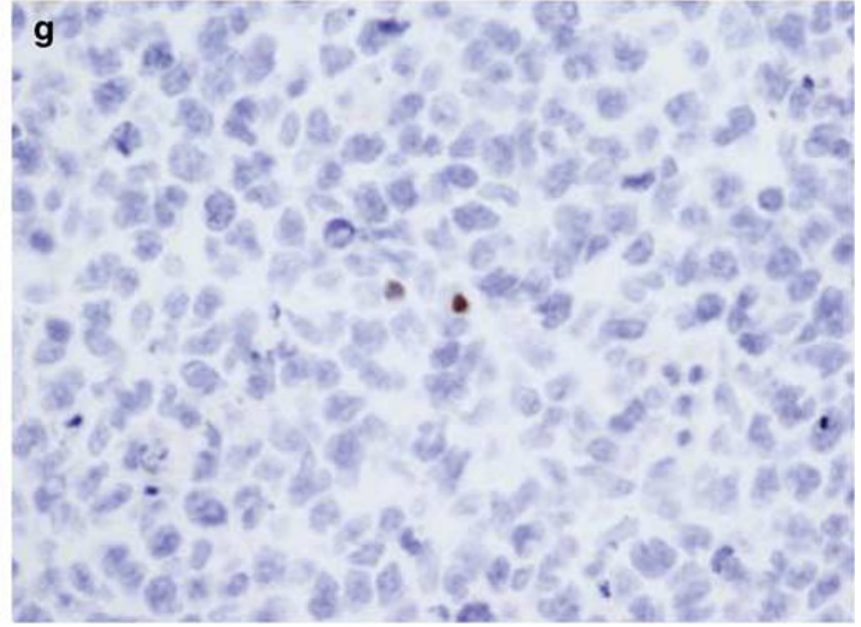

expression and almost all of the cases (15/16) showed positivity. Among 169 cases, 60 (36\%) were positive for FOXP3 (Figure 1f and g). Of the FOXP3 $(+)$ cases, 36 were included in the pleo medium type, accounting for $60 \%$, a significantly higher percentage than for the other 2 types. Moreover, only one case of ALCL (2\%) was positive for FOXP3, which was significantly lower than for the other two types.

\section{Immunohistochemical Analysis}

Immunohistochemical analysis was performed in all cases (169 cases) in CCR4 (Table 1 ). Only 96 cases, however, were additionally evaluated in CD4, CD25 and CD30 because of the limitation in the number of unstained sections. The lymphoma cells were mainly positive for CD4 and CD25. There was no significant difference between FOXP3 $(+)$ ATLL and FOXP3(-) ATLL in CD4 and CD25. The CD4 + CD25 + phenotype was detected in 80 cases (83\%), and 16 cases $(17 \%)$ did not show CD4 + CD25 + phenotype. But there was no significant difference in FOXP3-positive rate between the two groups (33/91 and $5 / 20 ; P=0.57)$. FOXP3(-) cases showed relatively higher positivity for CD30 due to the fact that almost all cases of ALCL showed CD30 positivity. We stained ATLL cases with the chemokine receptors CCR4 and CCR8, which have been identified as Treg-specific molecules. ${ }^{34}$ Almost all cases of ATLL $(95 \%)$ were positive for CCR4, while only about $34 \%$ were positive for CCR8. CCR4 was relatively more frequently expressed in FOXP3 $(+)$ than in FOXP3(-) type, although not significantly so $(P=0.12)$, while there was no difference in CCR8 frequency between the two types $(P=0.66)$.

\section{EBV Infection}

EBER in situ hybridization was used to analyze 169 cases (60 cases of FOXP3(+) and 109 of FOXP3(-)) 
Table 1 Pathological features and FOXP3 expression in ATLL

\begin{tabular}{|c|c|c|c|c|}
\hline & & FOXP3(+) & $F O X P 3(-)$ & P-value \\
\hline Morphology $(n=169)$ & $\begin{array}{l}\text { ALCL }(n=22) \\
\text { Pleo, large }(n=76) \\
\text { Pleo, medium } \\
(n=71)\end{array}$ & $\begin{array}{c}1 \\
23 \\
36\end{array}$ & $\left.\begin{array}{l}21 \\
53 \\
35\end{array}\right] * \square * *$ & \\
\hline EBER positivity $(n=169)$ & & $38 \%(23 / 60)$ & $11 \%(12 / 109)$ & $<0.0001$ \\
\hline CCR4 positivity $(n=169)$ & & $98 \%(59 / 60)$ & $93 \%(101 / 109)$ & 0.12 \\
\hline CCR8 positivity $(n=86)$ & & $32 \%(19 / 59)$ & $37 \%(10 / 27)$ & 0.66 \\
\hline \multirow{2}{*}{$\begin{array}{l}\text { Other markers positivity } \\
(n=96)\end{array}$} & CD4 & $94 \%(34 / 36)$ & $98 \%(59 / 60)$ & 0.29 \\
\hline & $\begin{array}{l}\text { CD25 } \\
\text { CD30 } \\
\text { CD4+CD25+ }\end{array}$ & $\begin{array}{l}92 \%(33 / 36) \\
14 \%(5 / 36) \\
83 \%(31 / 36)\end{array}$ & $\begin{array}{l}83 \%(50 / 60) \\
27 \%(16 / 60) \\
82 \%(49 / 60)\end{array}$ & $\begin{array}{l}0.25 \\
0.14 \\
0.57\end{array}$ \\
\hline
\end{tabular}

${ }^{*} P<0.05,{ }^{*} P<0.0005$.

(Table 1 and Figure 1). Cells with definitive EBV infection (EBER-positive cells) were detected in 35 cases $(21 \%)$, while $38 \%(23 / 60)$ of FOXP3 $(+)$ ATLL cases and only $11 \%(12 / 109)$ of FOXP3(-) ATLL cases showed EBV-infected cells. Finally, EBV-infected cells were significantly more frequently detected in the tissue of FOXP3 $(+)$ ATLL than in that of FOXP3(-) ATLL cases $(P<0.0001)$.

\section{Clinical Features}

The clinical findings are summarized in Table 2 . The 96 cases enrolled in our study comprised 34 FOXP3(+) and 62 FOXP3(-) cases, of which 40 cases were lymphomatous type and 56 acute type. There were 42 females and 54 males aged 27-90 years with a mean age of 63 years. The median age of FOXP3 $(+)$ cases was relatively lower than that of FOXP3(-) cases (58 and 64 years, respectively). The ratio of patients over age 60 years was relatively smaller for FOXP3(+) $(47 \%)$ than for FOXP3(-) cases $(68 \%)(P=0.09)$, and FOXP3 $(+)$ cases showed female predominance but FOXP3(-) cases did not (59 vs 35\%; $P<0.05$ ). However, other factors (clinical stage, clinical type (lymphoma and acute type), serum LDH and calcium elevation and extranodal site involvement including peripheral blood and bone marrow) did not show any significant differences between FOXP3 $(+)$ and FOXP3(-) cases. Therapy based on clinical data was administered to 94 patients, all of whom received chemotherapy (CHOP-like regimen) and 20 cases received radiation therapy. Nine cases received stem cell transplantation (SCT). Five patients received allogeneic SCT and four patients received autologous SCT. Among the nine cases who received SCT, five were FOXP3 $(+)$. Relatively more FOXP3 $(+)$ than FOXP3 $(-)$ cases received SCT
Table 2 Clinical features of FOXP3(+) ATLL and FOXP3(-) ATLL

\begin{tabular}{lccc}
\hline & FOXP3(+) & FOXP3(-) & P-value \\
& ATLL $(\mathrm{n}=34)$ & ATLL $(\mathrm{n}=62)$ & \\
\hline Median age & 58 & 64 & \\
Age range & $27-80$ & $35-90$ & 0.64 \\
Over 60 years & $16 / 34(47 \%)$ & $42 / 62(68 \%)$ & 0.09 \\
Sex (M/F) & $14 / 20$ & $40 / 22$ & 0.02 \\
Stage III or IV & $30 / 34(88 \%)$ & $51 / 62(83 \%)$ & 0.46 \\
Elevated LDH & $28 / 33(85 \%)$ & $50 / 62(84 \%)$ & 0.9 \\
Lymphoma type/ & $15 / 19$ & $25 / 37$ & 0.67 \\
acute type & & & \\
$\begin{array}{l}\text { Extranodal sites } \\
\text { involvement }\end{array}$ & $23 / 34(68 \%)$ & $50 / 62(80 \%)$ & 0.15 \\
$\begin{array}{l}\text { Elevated calcium } \\
\text { Stem cell }\end{array}$ & $9 / 32(28 \%)$ & $9 / 55(18 \%)$ & 0.22 \\
transplantation & $6 / 34(18 \%)$ & $3 / 60(5 \%)$ & 0.045 \\
& & & \\
\hline
\end{tabular}

${ }^{\mathrm{a}}$ Includes peripheral blood.

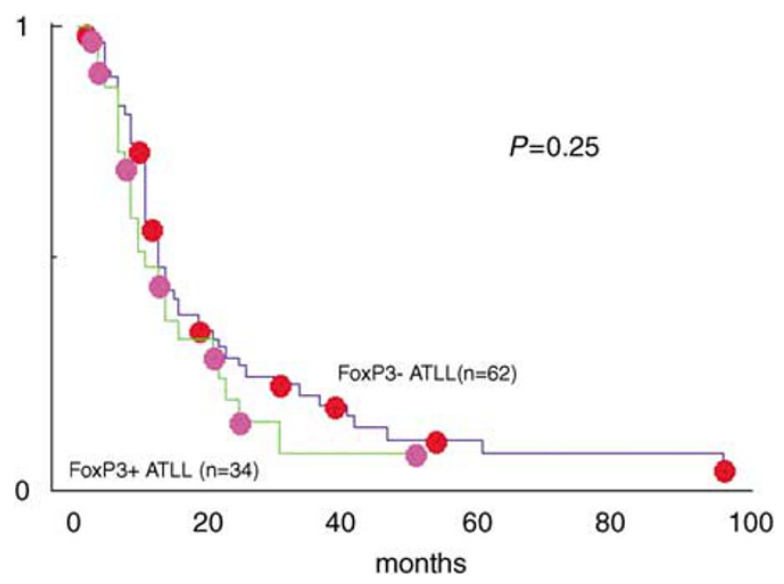

Figure 2 Overall survival (OS) of FOXP3(+ ) and FOXP3(-) ATLL $(n=96)$. There was no significant difference in OS.

$(P<0.05)$. Overall survival shown in Figure 2 demonstrates no significant difference between the two groups. 
Table 3 Ten cases suspected as immunosuppressive state

\begin{tabular}{|c|c|c|c|c|}
\hline Sex & Age & Clinical type & FOXP3 & Summary \\
\hline M & 66 & Lymphoma & + & $\begin{array}{l}\text { Severe diarrhea at disease onset. Strongyloides stercoralis infection was } \\
\text { proved }\end{array}$ \\
\hline M & 47 & Lymphoma & - & Cytomegalovirus pneumonia was proved in disease course \\
\hline $\mathrm{F}$ & 76 & Lymphoma & + & $\begin{array}{l}\text { At disease onset, she suffered from subcutaneous abscess that was refractory } \\
\text { to antibiotics therapy and prolonged during disease course }\end{array}$ \\
\hline $\mathrm{F}$ & 44 & Lymphoma & + & $\begin{array}{l}\text { After the first chemotherapy, herpes zoster infection and myocarditis with } \\
\text { Coxsackie B4 infection occurred, although neutrophils had already recovered }\end{array}$ \\
\hline $\mathrm{F}$ & 73 & Acute & + & $\begin{array}{l}\text { Herpes zoster infection was detected at disease onset. Cytomegalovirus infection } \\
\text { occurred in disease course }\end{array}$ \\
\hline M & 47 & Acute & + & $\begin{array}{l}\text { Esophageal candidiasis and herpes simplex infection occurred at disease onset. } \\
\text { Aspergillus pneumonia occurred in disease course }\end{array}$ \\
\hline $\mathrm{F}$ & 52 & Lymphoma & + & Cryptococcal meningitis occurred at disease onset \\
\hline $\mathrm{M}$ & 58 & Lymphoma & + & At the relapse, he suffered from scabies and inguinal herpes infection \\
\hline $\mathrm{N}$ & 66 & Acute & - & $\begin{array}{l}\text { Herpes zoster infection occurred at the first remission. Cytomegalovirus } \\
\text { pneumonia occurred at relapse }\end{array}$ \\
\hline $\mathrm{F}$ & 80 & Lymphoma & + & Cytomegalovirus and Pneumocystis carinii infection occurred in disease course \\
\hline
\end{tabular}

\section{Immunodeficient Cases}

During the clinical course, 10 of the 96 cases showed definitive immunodeficient status, as shown in Table 3, with a significantly higher probability for FOXP3 $(+)$ cases $(8 / 34 ; 24 \%)$ than for FOXP3(-) cases $(2 / 62 ; 3 \%)(P<0.005)$. Only one patient received autologous SCT, but other nine cases were treated with only chemotherapy without SCT. This suggests that immunodeficient status in these 10 patients was not induced by intensive therapy.

\section{Cytogenetic Analysis}

All 74 patients, comprising 26 FOXP $3(+)$ and 48 FOXP3(-) cases, showed abnormal karyotypes (Table 4; the Table containing the detailed cytogenetic findings can be obtained on request). Aneuploidy was observed in 18 FOXP3 $(+)$ cases (16 hyperdiploid, 1 hypodiploid, 1 nearly tetraploid) and in 44 FOXP3(-) cases (28 hyperdiploid, 10 hypodiploid, 5 nearly triploid, 1 nearly tetraploid). Aneuploidy was thus found significantly more frequently in the FOXP3 $(-)$ than in the FOXP3 $(+)$ type $(P<0.05)$. No specific recurrent abnormality was detected in either FOXP3(+) or FOXP3(-) cases. Simple numerical abnormality without structural abnormality was observed in 22 FOXP3 $(+)$ cases and 43 FOXP3(-) cases. The average number of numerical abnormalities was significantly higher in FOXP3(-) cases (6.8) than in FOXP3(+) cases (2.8) $(P<0.0001)$. Structural abnormalities were detected in 71 cases, while only 3 cases were free from structural abnormalities, and all of them were negative for FOXP3. The average number of breaks in FOXP3(+) and FOXP3(-) cases was not significantly different (7.3 vs 8.6, $P=0.35)$. We focused on abnormalities on Xp11-q13, where the FOXP3 gene is located, but only two cases, one FOXP3 $(+)$ and one FOXP3(-), showed amplifica-
Table 4 Cytogenetic features and FOXP3 expression in ATLL

\begin{tabular}{lccc}
\hline & $\begin{array}{c}\text { FOXP3(+) } \\
(\mathrm{n}=26)\end{array}$ & $\begin{array}{c}\text { FOXP3(-) } \\
(\mathrm{n}=48)\end{array}$ & P-value \\
\hline $\begin{array}{l}\text { Aneuploidy } \\
\begin{array}{l}\text { Number of simple numerical } \\
\text { abnormalities (average) }\end{array}\end{array}$ & 2.8 & $64(99 \%)$ & $<0.05$ \\
$\begin{array}{l}\text { Number of structural } \\
\text { abnormalities (average) }\end{array}$ & 7.3 & 8.6 & $<0.0001$ \\
\hline
\end{tabular}

tion of Xp11-q13 and only one FOXP3(-) case showed translocation of Xp11-q13 (data not shown).

\section{Discussion}

This study shows for the first time that FOXP3 expression in ATLL is associated with a clinically and pathologically immunodeficient state. About $36 \%$ of the ATLL cases enrolled in this study were positive for FOXP3, indicating that ATLL can be divided into two types: FOXP3(+) and FOXP3(-). The percentage of FOXP3 $(+)$ type was consistent with previously reported ratios ${ }^{22-24}$ and confirms the heterogeneity of ATLL.

Various reports have described the phenotypic features of Tregs except for CD4 and CD25. These include cytotoxic T-lymphocyte-associated antigen 4, glucocorticoid-induced tumor necrosis factor receptor family-related gene and CD103 $\left(\alpha_{\mathrm{E}}\right.$ integrin). ${ }^{35-37}$ Recently, Iellem et $a l^{34}$ reported that CCR4 and CCR8 were relatively specifically expressed on Tregs, and they speculated that these chemokine receptors may guide Treg cells to sites of antigen presentation in secondary lymphoid tissues and inflamed areas to attenuate T-cell activation. ${ }^{34}$ CCR4 and CCR8 expression on ATLL cells has also been reported in association with skin invasion ${ }^{38}$ or autocrine antiapoptotic stimulation of ATLL cells. ${ }^{39}$ We could not detect any correlation between CCR8 
expression and FOXP3 expression, but FOXP3(+) cases expressed CCR4 relatively more frequently, although not significantly so, than did FOXP3(-) cases and this may reflect the nature of Tregs in FOXP3 $(+)$ ATLL. Ishida et $a^{21}$ found that the CD4+ CD25 + CCR4 + phenotype is selectively associated with normal Tregs.

EBV-positive LPDs are often associated with an immunodeficient state. AIDS-related LPD, posttransplant LPD and senile EBV-positive LPD are representative immunodeficient states related to EBV-positive LPD. ${ }^{40,41}$ In healthy carriers, EBVpositive cell proliferation is well regulated by EBV-specific cytotoxic T lymphocytes (CTLs). In the immunodeficient state, however, EBV-infected cells proliferate with a decline in EBV-specific cytotoxic T-cell functions. ${ }^{42}$ Actually, regression of posttransplant lymphoproliferative disorder may occur in some cases if immunosuppression is reduced or the patient has been infused with EBV-specific CTLs generated from the original allogeneic donor. ${ }^{43,44} \mathrm{In}$ Hodgkin's lymphoma, Hodgkin and Reed-Sternberg (HRS) cells are often infected with the EBV, and regulatory T-cell infiltration around HRS cells coincides with the suppression of latent membrane antigen-specific CD8 + T-cell function and helps HRS cells to survive. ${ }^{45,46}$ It is well known that EBV-infected cells, the majority of them B cells, emerge in peripheral T-cell lymphoma, including ATLL. ${ }^{1,32,47,48}$ With reference to the new WHO classification, Kikuchi et al ${ }^{1}$ described the expansion of EBV-infected cells as a secondary event subsequent to underlying immunodeficiency in ATLL patients. Katsuki et $a l^{6}$ previously reported that T-cell control of EBV-infected $B$ cells was impaired in healthy HTLV-1 carriers. The higher frequency of EBV-positive cells in FOXP3 $(+)$ than in FOXP3(-) cases indicates that FOXP3-positive lymphoma cells may have a stronger suppressive effect on the T-cell control of EBV-positive cells and thus induce their proliferation.

Our cytogenetic analysis did not detect specific recurrent abnormalities, similar to previous studies. ${ }^{49,50}$ However, FOXP3(-) cases included more cases with aneuploidy and showed more numerical chromosome abnormalities than FOXP3 $(+)$ cases. In serially studied ATL patients, only normal or simple abnormal karyotypes were detected at diagnosis, while complex karyotypes appeared later at relapse. ${ }^{51,52}$ These findings are compatible with the hypothesis of multistep carcinogenesis in ATLL. ${ }^{53}$ Therefore, the occurrence of relatively simpler cytogenetic abnormalities in FOXP3 $(+)$ cases may indicate a relatively earlier stage in multistep carcinogenesis than in FOXP3(-) cases. This implies that FOXP3 expression may be lost with disease progression, and it is explicable for the different FOXP3 expression among each of the cases.

Clinically, there was no significant difference in prognosis between FOXP3(+) ATLL and FOXP3(-)
ATLL. Roncador et $a l^{22}$ reported that FOXP3 $(+)$ ATLL showed a more aggressive clinical course than FOXP3(-) ATLL, but that the difference was not significant. While our study analyzed 96 ATLL cases, many more than those enrolled in previous studies, no significant difference in overall survival rate between the two types of ATLL could be identified. FOXP3 $(+)$ ATLL cells may suppress tumor immunity and promote tumor growth, but other factors, especially relatively younger age and more cases with SCT than in the case of FOXP3(-), may compensate for some disadvantages (eg, immunodeficient status) and improve the prognosis for FOXP3( +) ATLL.

The mechanisms of immunosuppression in ATLL have been the subject of many discussions. The immunodeficient state is also seen in HTLV-1 carriers and patients with HAM/TSP without malignancies and is associated with infections caused by various fungi, viruses and protozoa., ${ }^{4,6,54}$ In one experiment, inoculation of rabbits with a cell line infected with HTLV-1 resulted in thymic atrophy, which was found to be associated with infiltration of HTLV-1-infected cells into the thymus. ${ }^{55}$ Impaired production of naïve $\mathrm{T}$ lymphocytes in HTLV1-infected individuals was reported recently. ${ }^{56}$ The results of our study indicate that ATLL cells may function as Treg-like cells and induce the immunosuppressive state described above, especially in FOXP3(+) cases.

In conclusion, FOXP3 expression was found to be associated with an immunosuppressive clinical state, proliferation of EBV-positive cells in tissue, relatively simple cytogenetic changes and smaller lymphoma cells, and especially with an exclusively anaplastic morphology. These findings disclose that FOXP3 expression is meaningful rather than aberrant and reflects specific biological functions in ATLL.

\section{Acknowledgements}

This study was supported in part by Grants-in-Aid from the Ministry of Education, Science and Culture, Japan. We thank Mrs Takasu K and Professor Piris MA for their technical advice.

$\mathrm{KK}$ and $\mathrm{KO}$ designed the study, KK executed the study and analyzed data, KK wrote the paper and JS, YS, YN, KY, KS, SY, HK, MT, MK, UA, RA, MK and NS partly contributed to the analysis of data.

\section{References}

1 Kikuchi M, Jaffe ES, Ralfkiaer E. Adult T cell leukaemia/lymphoma In: Jaffe ES, Harris NL, Stein H, Vardiman JW (eds). Pathology and Genetics of Tumours of Haematopoietic and Lymphoid Tissues. World Health Organization Classification of Tumours. IARC Press: Lyon, France, 2001, pp 200-203. 
2 Yamada Y. Phenotypic and functional analysis of leukemic cells from 16 patients with adult T-cell leukemia/lymphoma. Blood 1983;61:192-199.

3 White JD, Zaknoen SL, Kasten-Sportes C, et al. Infectious complications and immunodeficiency in patients with human T-cell lymphotropic virus Iassociated adult T-cell leukemia/lymphoma. Cancer 1995;75:1598-1607.

4 Moriyama K, Muranishi H, Nishimura J, et al. Immunodeficiency in preclinical smoldering adult T-cell leukemia. Jpn J Clin Oncol 1988;18:363-369.

5 Pagliuca A. Strongyloides hyperinfection in adult T-cell leukaemia/lymphoma. Br J Haematol 1999;105:1.

6 Katsuki T, Katsuki K, Imai J, et al. Immune suppression in healthy carriers of adult T-cell leukemia retrovirus (HTLV-I): impairment of T-cell control of Epstein-Barr virus-infected B-cells. Jpn J Cancer Res 1987;78: 639-642.

7 Sakaguchi S, Sakaguchi N, Asano M, et al. Immunologic self-tolerance maintained by activated $\mathrm{T}$ cells expressing IL-2 receptor alpha-chains (CD25). Breakdown of a single mechanism of self-tolerance causes various autoimmune diseases. J Immunol 1995;155: 1151-1164.

8 Takahashi T, Kuniyasu Y, Toda M, et al. Immunologic self-tolerance maintained by CD25+CD4+ naturally anergic and suppressive $\mathrm{T}$ cells: induction of autoimmune disease by breaking their anergic/suppressive state. Int Immunol 1998;10:1969-1980.

9 Shevach EM, McHugh RS, Piccirillo CA, et al. Control of T-cell activation by CD4+ CD25+ suppressor T cells. Immunol Rev 2001;182:58-67.

10 Shevach EM. Certified professionals: CD4(+)CD25(+) suppressor T cells. J Exp Med 2001;193:F41-F46.

11 North RJ, Bursuker I. T cell-mediated suppression of the concomitant antitumor immune response as an example of transplantation tolerance. Transplant Proc 1984;16:463-469.

12 Liyanage UK, Moore TT, Joo HG, et al. Prevalence of regulatory $\mathrm{T}$ cells is increased in peripheral blood and tumor microenvironment of patients with pancreas or breast adenocarcinoma. J Immunol 2002;169: 2756-2761.

13 Yang ZZ, Novak AJ, Ziesmer SC, et al. Attenuation of CD8(+) T-cell function by CD4(+)CD25(+) regulatory T cells in B-cell non-Hodgkin's lymphoma. Cancer Res 2006;66:10145-10152.

14 Hisaeda H, Maekawa Y, Iwakawa D, et al. Escape of malaria parasites from host immunity requires CD4+ CD25+ regulatory T cells. Nat Med 2004;10:29-30.

15 Hori S, Nomura T, Sakaguchi S. Control of regulatory T cell development by the transcription factor Foxp3. Science 2003;299:1057-1061.

16 Roncador G, Brown PJ, Maestre L, et al. Analysis of FOXP3 protein expression in human CD4+CD25+ regulatory $\mathrm{T}$ cells at the single-cell level. Eur J Immunol 2005;35:1681-1691.

17 Fontenot JD, Gavin MA, Rudensky AY. Foxp3 programs the development and function of CD4+CD25+ regulatory T cells. Nat Immunol 2003;4: 330-336.

18 Khattri R, Cox T, Yasayko SA, et al. An essential role for Scurfin in CD4+CD25+ T regulatory cells. Nat Immunol 2003;4:337-342.

19 Hori S, Sakaguchi S. Foxp3: a critical regulator of the development and function of regulatory $\mathrm{T}$ cells. Microbes Infect 2004;6:745-751.
20 Karube K, Ohshima K, Tsuchiya T, et al. Expression of FoxP3, a key molecule in CD4CD25 regulatory T cells, in adult T-cell leukaemia/lymphoma cells. $\mathrm{Br} \mathrm{J}$ Haematol 2004;126:81-84.

21 Ishida $\mathrm{T}$, Inagaki $\mathrm{H}$, Utsunomiya $\mathrm{A}$, et al. CXC chemokine receptor 3 and CC chemokine receptor 4 expression in T-cell and NK-cell lymphomas with special reference to clinicopathological significance for peripheral T-cell lymphoma, unspecified. Clin Cancer Res 2004;10:5494-5500.

22 Roncador G, Garcia JF, Maestre L, et al. FOXP3, a selective marker for a subset of adult T-cell leukaemia/ lymphoma. Leukemia 2005;19:2247-2253.

23 Kohno T, Yamada Y, Akamatsu N, et al. Possible origin of adult T-cell leukemia/lymphoma cells from human $\mathrm{T}$ lymphotropic virus type-1-infected regulatory T cells. Cancer Sci 2005;96:527-533.

24 Matsubara Y, Hori T, Morita R, et al. Phenotypic and functional relationship between adult T-cell leukemia cells and regulatory $\mathrm{T}$ cells. Leukemia 2005;19: 482-483.

25 Chen S, Ishii N, Ine $\mathrm{S}$, et al. Regulatory $\mathrm{T}$ cell-like activity of Foxp3+ adult $\mathrm{T}$ cell leukemia cells. Int Immunol 2006;18:269-277.

26 Yano H, Ishida T, Inagaki A, et al. Regulatory T-cell function of adult T-cell leukemia/lymphoma cells. Int J Cancer 2007;120:2052-2057.

27 Takeshita M, Akamatsu M, Ohshima K, et al. CD30 (Ki-1) expression in adult T-cell leukaemia/lymphoma is associated with distinctive immunohistological and clinical characteristics. Histopathology 1995;26: 539-546.

28 Takeshita M, Ohshima K, Akamatsu M, et al. CD30positive anaplastic large cell lymphoma in a human T-cell lymphotropic virus-I endemic area. Hum Pathol 1995;26:614-619.

29 Ohshima K, Suzumiya J, Sato K, et al. Nodal T-cell lymphoma in an HTLV-I-endemic area: proviral HTLV-I DNA, histological classification and clinical evaluation. Br J Haematol 1998;101:703-711.

30 Ohshima K, Suzumiya J, Kato A, et al. Clonal HTLV-Iinfected CD4+ T-lymphocytes and non-clonal nonHTLV-I-infected giant cells in incipient ATLL with Hodgkin-like histologic features. Int J Cancer 1997;72: 592-598.

31 Karube K, Suzumiya J, Okamoto M, et al. Adult T-cell lymphoma/leukemia with angioimmunoblastic T-cell lymphomalike features: report of 11 cases. Am J Surg Pathol 2007;31:216-223.

32 Dupuis J, Emile JF, Mounier N, et al. Prognostic significance of Epstein-Barr virus in nodal peripheral T-cell lymphoma, unspecified: a Groupe d'Etude des Lymphomes de l'Adulte (GELA) study. Blood 2006; 108:4163-4169.

33 Ohshima K, Kikuchi M, Masuda Y, et al. Defective provirus form of human T-cell leukemia virus type I in adult T-cell leukemia/lymphoma: clinicopathological features. Cancer Res 1991;51:4639-4642.

34 Iellem A, Mariani M, Lang R, et al. Unique chemotactic response profile and specific expression of chemokine receptors CCR4 and CCR8 by CD4(+)CD25(+) regulatory T cells. J Exp Med 2001;194:847-853.

35 Leithauser F, Meinhardt-Krajina T, Fink K, et al. Foxp3-expressing CD103+ regulatory T cells accumulate in dendritic cell aggregates of the colonic mucosa in murine transfer colitis. Am J Pathol 2006;168: 1898-1909. 
36 Shimizu J, Yamazaki S, Takahashi T, et al. Stimulation of CD25(+)CD4(+) regulatory $\mathrm{T}$ cells through GITR breaks immunological self-tolerance. Nat Immunol 2002;3:135-142.

37 Takahashi T, Tagami T, Yamazaki S, et al. Immunologic self-tolerance maintained by CD25(+)CD4(+) regulatory $\mathrm{T}$ cells constitutively expressing cytotoxic T lymphocyte-associated antigen 4. J Exp Med 2000;192: 303-310.

38 Yoshie O, Fujisawa R, Nakayama T, et al. Frequent expression of CCR4 in adult T-cell leukemia and human T-cell leukemia virus type 1-transformed $\mathrm{T}$ cells. Blood 2002;99:1505-1511.

39 Ruckes T, Saul D, Van Snick J, et al. Autocrine antiapoptotic stimulation of cultured adult T-cell leukemia cells by overexpression of the chemokine I-309. Blood 2001;98:1150-1159.

40 Oyama T, Ichimura K, Suzuki R, et al. Senile EBV+ Bcell lymphoproliferative disorders: a clinicopathologic study of 22 patients. Am J Surg Pathol 2003;27:16-26.

41 Harris NL, Swerdlow SH, Frizzera G, Knowles DM. Post-transplant lymphoproliferative disorders In: Jaffe ES, Harris NL, Stein H, Vardiman JW (eds). Pathology and Genetics of Tumours of Haematopoietic and Lymphoid Tissues. World Health Organization Classification of Tumours. IARC Press: Lyon, France, 2001, pp 264-269.

42 Baumforth KR, Young LS, Flavell KJ, et al. The Epstein-Barr virus and its association with human cancers. Mol Pathol 1999;52:307-322.

43 Papadopoulos EB, Ladanyi M, Emanuel D, et al. Infusions of donor leukocytes to treat Epstein-Barr virus-associated lymphoproliferative disorders after allogeneic bone marrow transplantation. N Engl J Med 1994;330:1185-1191.

44 Rooney CM, Smith CA, Ng CY, et al. Use of gene-modified virus-specific $\mathrm{T}$ lymphocytes to control Epstein-Barr-virus-related lymphoproliferation. Lancet 1995;345:9-13.

45 Gandhi MK, Lambley E, Duraiswamy J, et al. Expression of LAG-3 by tumor-infiltrating lymphocytes is coincident with the suppression of latent membrane antigen-specific CD8+ T-cell function in Hodgkin lymphoma patients. Blood 2006;108:2280-2289.
46 Ishida T, Ishii T, Inagaki A, et al. Specific recruitment of CC chemokine receptor 4-positive regulatory T cells in Hodgkin lymphoma fosters immune privilege. Cancer Res 2006;66:5716-5722.

47 Tobinai K, Ohtsu T, Hayashi M, et al. Epstein-Barr virus (EBV) genome carrying monoclonal B-cell lymphoma in a patient with adult T-cell leukemialymphoma. Leuk Res 1991;15:837-846.

48 Ho JW, Ho FC, Chan AC, et al. Frequent detection of Epstein-Barr virus-infected B cells in peripheral T-cell lymphomas. J Pathol 1998;185:79-85.

49 Itoyama T, Chaganti RS, Yamada Y, et al. Cytogenetic analysis and clinical significance in adult T-cell leukemia/lymphoma: a study of 50 cases from the human T-cell leukemia virus type-1 endemic area, Nagasaki. Blood 2001;97:3612-3620.

50 Kamada N, Sakurai M, Miyamoto K, et al. Chromosome abnormalities in adult T-cell leukemia/lymphoma: a karyotype review committee report. Cancer Res 1992;52:1481-1493.

51 Sanada I, Tanaka R, Kumagai E, et al. Chromosomal aberrations in adult $T$ cell leukemia: relationship to the clinical severity. Blood 1985;65:649-654.

52 Shimoyama M, Abe T, Miyamoto K, et al. Chromosome aberrations and clinical features of adult $\mathrm{T}$ cell leukemia-lymphoma not associated with human $\mathrm{T}$ cell leukemia virus type I. Blood 1987;69:984-989.

53 Okamoto T, Ohno Y, Tsugane S, et al. Multi-step carcinogenesis model for adult T-cell leukemia. Jpn J Cancer Res 1989;80:191-195.

54 Tachibana N, Okayama A, Ishizaki J, et al. Suppression of tuberculin skin reaction in healthy HTLV-I carriers from Japan. Int J Cancer 1988;42:829-831.

55 Simpson RM, Zhao TM, Hubbard BS, et al. Experimental acute adult $\mathrm{T}$ cell leukemia-lymphoma is associated with thymic atrophy in human $\mathrm{T}$ cell leukemia virus type I infection. Lab Invest 1996;74: 696-710.

56 Yasunaga J, Sakai T, Nosaka K, et al. Impaired production of naive $\mathrm{T}$ lymphocytes in human T-cell leukemia virus type I-infected individuals: its implications in the immunodeficient state. Blood 2001;97: 3177-3183. 